It is quite common in hospital clinics for the operator to lecture to his class while leaning over his work, and, frequently straightening up to address the students, and thus many valuable minutes are lost. A very wise practice is now being introduced in the German clinies. The professor operates, while one of his clinical assistants lectures to the class, or vice versa. The operator can thus concentrate his mind on the important task before him. Professor Albert, of Vienna, lectured to the students while his assistant, Ewald, operated. This method is advantageous to both patient and student. But few are endowed with the ability to lecture and operate simultaneously.

An operation should be done with despatch, without the semblance of undue haste or attempt at show, flourish or brilliancy. Such "speed" should be consistent with good conscientious work and the best results. Despatch in surgical operations is often misconstrued as haste and carelessness by jealous rivals. The operator is rapid whose equipment is thorough from his anesthetizer and first assistant to the application of the safety-pin which secures the final turn of the bandage. He accomplishes his object who does not allow his plans to be modified by suggestions from visitors or guests, who is prepared to promptly combat any emergency that may arise, who operates deliberately, who does not drop his instruments on the floor, and who, in picking up an instrument from the tray, does so for a definite purpose. Such an operator knows what he wants two or three stages in advance, and gives his orders accordingly, so that there shall be no loss of time. His assistants are well trained ("team work") and comprehend his wants by a look or gesture, thus avoiding misunderstanding, conflicting orders and collisions.

It is in the saving of the minutes and avoidance of unnecessary delays that the minimum amount of time is consumed in performing the operation. Such methods should constitute "rapid operating."

\section{VENEREAL DISEASE AS A SOCIAL PROBLEM.*}

$$
\begin{aligned}
& \text { W. C. GATES, M.D. } \\
& \text { ROCKLAND, MICH. }
\end{aligned}
$$

When studying medicine I was taught, not only by one but by many, that if I would attain to the greatest degree of success in the profession I must treat every patient who presented, no matter what his social position or standing, age, or other condition, as if he were infected with venereal disease until I had proved to the contrary. At that time I could not fully credit the statement and questioned the observation of the men who made it. I entered practice about ten years ago, in a town with an average population of 500, which for all practical purposes of this paper is an ordinary country village, isolated from the rest of the world and a great distance from any city. There was no house of prostitution in the township, and no public prostitute has existed within its borders since my residence there, but time and experience have convinced me that my teachers were right in their statement.

Syphilis is a terrible disease and is so recognized by the laity, while the great majority regard gonorrhea as a trivial affection. To my mind it is tenfold more terrible than syphilis, while both diseases cause untold suffering to innocent parties, and during my very limited experience I have seen several blind from the dis-

- Presented to the Section on Hygiene and Sanitary Science, at the Fifty-first Annual Meeting of the American Medical Association, held at Atlantic City, N. J., June 5-8, 1900. ease. The year I entered the town a young man from one of the best families graduated from one of our schools; a few years later, while on a business trip outside, he contracted gonorrhea, was treated and, as he supposed, cured by a frieend who had suffered several times in the same way. Soon after his return home he was married to a young woman whom I remember as a bright, robust, rosy-cheeked schoolgirl. Since then I have treated the man for stricture and his wife for all the evils following a gonorrheal infection of the pelvic organs. She is pale, anemic, a daily sufferer, and spends nearly a week out of each month in bed. Without children, in a beautiful home, she will drag out her life of misery and suffering.

A farmer's daughter, whom I remember as a beautiful schoolgirl, a perfect type of physical strength, two years ago married a man who bragged of the number of times he had contracted gonorrhea. Soon after marriage her troubles began, her strength failed and physical exertion became a source of discomfort and pain until she was unable to do her own housework. A few months ago I operated on her for pelvic peritonitis.

A year ago I knew a man, with a wife and four children, who possessed a good income and a happy comfortable home. He contracted gonorrhea, infected his wife before he knew it, became frightened and used socalled heroic treatment, and is now at Mt. Clemens under treatment for gonorrheal rheumatism, his wife is in a Chicago hospital to undergo an operation for salpingitis, the home is sold to pay the expenses, and the children are cared for by strangers.

I would ask my hearers to lay aside all prejudice and consider this subject in the true scientific spirit, going back to the fundamental underlying principles: 1 , the passions actuating those who keep this evil in existence; 2 , the breeding of children and the hereditary mental influence to which they are subjected; 3 , the want of police and medical supervision through a morbid sentiment and a lack of knowledge in a class which wields the greatest influence.

I will first define a passion as a certain movement of the mind which not only influences, but predominates and controls the entire organism. What is the one supreme passion in man? What is the one supreme passion which actuates and controls, not only man, but all living organisms, without which, if suppressed, all life would soon cease to exist? The answer is plain-the sustenance of life. The passion which ranks next to this and nearly equals it in power is the propagation of life. If either of these passions were suppressed all life would soon cease to exist. They are unchangeable laws of Nature and no arbitrary law of society can suppress them or control them except to a very limited extent. These facts should never be lost to sight. Prostitution finds the reason for its existence in one of these passions, and if society would protect itself from the evils arising from prostitution it must study the subject carefully and act on reason instead of prejudice.

I believe much of the evil can be prevented and, as the acme of medical science is the prevention of disease, that this problem is pre-eminently one for the attention of the Association. It can not be left to the church, as she is unable to cope with it, and her influence, when brought to bear on this subject, has invariably been unsatisfactory. Churchmen are educated along different lines, seldom taught to differentiate fact from theory, or to reason from effect to cause, and they appeal largely to the sympathies and prejudices of those whom 
they would influence. Frequently, in times past, a few individuals have made a careful study of this phase of social life and succeeded in passing laws in some communities which have greatly mitigated the evils to which I have called attention, but the church has usually succeeded in sweeping them off the books.

Prostitution has existed under every social system of which the world has knowledge. Lecky, in his "History of European Morals," says : "Under these circumstances, there has arisen in society, a figure which is certainly the most mournful, and in some respects the most awful upon which the eye of the moralist can dwell. That unhappy being whose very name is a shame to speak. who counterfeits with a cold heart the transports of affection and submits herself as the passive instrument of lust; who is scorned and insulted as the vilest of her sex, and doomed for the most part, to discase and abject wretchedness, and an early death, appears in every age as the perpetual symbol of degradation and the sinfulness of man. Herself the supreme type of vice, she is ultimately the most efficient guardian of virtue. But for her the unchallenged purity of countless happy homes would be polluted, and not a few who in the pride of their untempted chastity, think of her with an indignant shudder, would have known the agony of remorse and of despair. On that one degraded and ignoble form are concentrated the passions which might have filled the world with shame. She remains, while creeds and civilizations rise and fall, the eternal priestess of humanity, blasted for the sins of the people."

While prostitution may be a necessary evil under our present social system, the experience of the past and the opinions of the best posted men in other nations and in our own country, prove beyond question that many of the resultant evils are not necessary and may, to a great extent, be prevented. As a step in this direction, I would suggest the American MEDical AssoCIATION invite the most able and prominent men throughout the country, considered to be the best posted on this and relative subjects, to a conference for the purpose of adopting such measures as, in their judgment, will result in the greatest good to the race and to society. I would ask not only physicians but police and other officials from our great cities, and any one who may be qualified to speak with authority on the subject under discussion.

Personally, I believe it is a mistake to try to, and an impossibility to suppress prostitution by passing laws and imposing penalties, but that society may eliminate and possibly eradicate the vice, by means of education and more careful breeding. I am of the opinion that less than 10 per cent. of the children born are the result of an actual desire for children backed by an intelligent study in an effort to breed and raise the best. This would leave over 90 per cent. born as the result of accident, while following the pursuit of physical pleasure, which must certainly have a great influence on the race and on the problems we are now considering. Out of this 90 per cent., a portion will most surely be born with perverted and abnormal instincts and passions.

A physically perfect man, standing high financially, and occupying a prominent place in society, may have a deformed moral nature which he recognizes and covers up: or, again, he has never thought of nor been educated on sexual relations. He marries a refined and highly-cultured woman. Ordinarily a model man, he occasionally finds some jolly companions, winds up with a big spree, goes home drunk, sick, and filthy, revolting to his wife and family. His wife is horrified and disgusted, and while he insists on his marital rights, she loathes the contact but is compelled to submit. If conception takes place what kind of an individual will be developed? If the mental qualifications be derived from the mother, a sexually cold and passionless being; if from the father, possibly the opposite extreme. If the mother feels that conception has taken place, broods over her troubles, becomes reckless, tries to murder the child before it is born and fails, a graver element is added to the hereditary influences acting on the child.

Prostitution is a very great evil and its suppression would be a desirable thing, but so long as a great majority of the children born are subject to the worst hereditary influences associated with the sexual passion, and the question of how to breed and raise the best is seldom considered, I do not think its suppression possible. An individual is what he is born, plus his environment. The environment may be changed, but the other qualifications, such as stature, etc., are unchangeable, except to a very limited extent; therefore, some individuals are no more to blame for being prostitutes than others are for having red hair, or blue eyes. The enaction of proper laws to control prostitution and restrict the evils arising from it, with the best measures possible in educating the coming generations on these subjects, I believe is the best that can be done at the present time.

Social purity should be one of the ideal aims of society, and I believe its nearest attainment will be found through the means of education. Our medical schools should give more thorough instruction in sexua] hygiene and physiology. Medical men can have great influence in moulding public opinion and causing people to give their children proper instruction in sexual matters. In a majority of our homes at present, if a child dares to ask a question pertaining to sexual matters, it is either lied to or deceived, or silenced in such a way that its mind receives a great shock. That all living organisms reproduce themselves is a fact which may be taught a child with plenty of every-day illustrations, without any element of sensuality presenting itself.

I think that the most wofully ignorant of all classes on such subjects are the clergymen and teachers, and as they wield immense influence their education should not be neglected; and unless special attention be given to the leaders of the churches, they will oppose all efforts along this line, because the truth runs counter to their pet prejudice on the subject of morality. While the church influence is unsatisfactory in the extreme, it is so through ignorance and prejudice. To those who will investigate this subject farther and wish positive and definite information, I would suggest a study of Lecky's "History of European Morals"; Sanger's "History of Prostitution"; Wier's "Lust and Religion"; Lydston's "Text-book of Venereal and Sexual Diseases"; and such other books as will suggest themselves in reading these.

Removal of Great Iengths of Intestine.-Blayney ( $D u b$. lin Journal of Medical Sciences, March) reports a case of removal of 8 feet $4 \frac{1}{2}$ inches of intestine from a boy, aged 10 . He had been run over by a wagon loaded with grain, the wheels passing over the lumbar region while he was lying on his face. Laparotomy was performed seventeen hours after his admission to the hospital and he recovered, but suffers from looseness of the bowels and occasional vomiting, and exhibits also an abnormally great appetite. From an analysis made on thirty-three of his cases in which over one meter of intestine was removed from human subjects, he concludes that where less than 6 feet $61 \%$ inches are removed, intestinal symptoms are, as a rule. absent, but where more, present. 